\title{
CON NICANOR PARRA POR EL LAGO MÁS LARGO DE CHILE
}

\section{FLORIDOR PÉREZ}

\section{DESCONFÍO DE LOS HOMENAJES LITERARIOS}

ASI TODOS ME recuerdan el funeral del fundador del Campesinos Football Club de no diré dónde. En el camposanto lo despide su mejor amigo, viejo crack y actual presidente: -"Cómo olvidar aquella tarde gloriosa en que pasaba el tiempo y no llegaba el gol que nos haría por fin alzar la Copa. En el último minuto, mi compadre agarra la esférica en el círculo central, se corre pa' la punta izquierda, pasa uno dos tres adversarios y casi del banderín del córner manda un tremendo pase al área y... igooool... del que habla..."!

Y si ahora me atrevo a ser "el que habla", es solo porque, aparte de artículos críticos, el director de Atenea desea "reunir testimonios, en los que caben la relación con Parra, alguna anécdota personal, etc." Bien, me digo, si el mismísimo presidente del Club Deportivo Universidad de Concepción nos hace tan oportuno pase iquién podría negarse a usar la cabeza, por dura que sea?

* Poeta y profesor normalista. Actual profesor del Curso-Taller de Poesía, Universidad Adolfo Ibáñez. Director Taller de Poesía de la Fundación Pablo Neruda. Santiago, Chile. Correo: floridorpoesia@gmail.com 


\title{
MI PRIMER PARRA
}

Mis lecturas de poesía hasta 1951 estuvieron dominadas en el hogar por Los titanes de la poesía universal, y en el colegio por El lector chileno, de Manuel Guzmán Maturana, y El niño chileno de César Bunster, por lo que supuse que fue en uno de ellos que leí por primera vez al poeta. Tan seguro estuve que, treinta años después, en el Museo Pedagógico de Santiago revisé todos los libros de lectura usados entre 1940 y 1950.

¿Qué buscaba? Un poema del que solo recordaba su autor, Nicanor Parra, y su tema, Manuel Rodríguez.

-Pero ese es un poema de Pablo Neruda -solían decirme, y hasta un funcionario recordó que alguna vez le pidieron el poema "Una aventura de Manuel Rodríguez".

-Sí, hay uno de Neruda y esa "Aventura" es de Pezoa Véliz, pero yo busco otro, de Parra.

-Nunca lo he leído... jamás lo he visto -solían opinar-, debe haber una confusión...

La había, y la descubrí tiempo después. Buscando uno de esos libros que extraviamos en nuestros estantes y que aparecen justo cuando ya no los buscamos, atrajo mi atención la colorida portada de Panorama y color de Chile, de Antonio Roco del Campo. Publicado por Ediciones Ercilla en 1939, estaba firmado así por mi padre: "Valdivia 31 de agosto de 1952".

Ese no es un año cualquiera para mí, y lo iba repasando mentalmente mientras hojeaba el libro al azar: en marzo ingresé a la Escuela Normal, en octubre cumplí quince años, en noviembre coroné a Juanita como Reina de la Primavera del barrio Las Ánimas con mi primer poema laureado... hasta que en su página 73 el Panorama me sorprende con este título:

\author{
Aventura de Manuel Rodríguez \\ (por Nicanor Parra) \\ Todo lo que digo aquí \\ es cierto y ha sucedido \\ tal como me lo enseñaron \\ en la escuela cuando niño. \\ Una vez iba un soldado \\ andando por un camino, \\ corazón a flor de pecho \\ las manos en los bolsillos. \\ Iba si no me equivoco
}


algo así como dormido, como si fuera despierto casi como a medio filo ...

Todos los soldados que conocí hasta entonces se lucían marchando en Fiestas Patrias y vivian con honor o morían con gloria en los actos escolares, por lo que éste que iba de mano en bolsillo, semidormido como nosotros en clase de Historia y para colmo casi como a medio filo, debió resultarme tan querible como esos amigos de infancia que parecen inseparables hasta que un día se alejan y no volvemos a verlos más.

Y como ocurre con ellos, me alegró este reencuentro casual en un estante, tanto como el 2006 me apenó su ausencia en las Obras completas publicadas en España. Pienso que se merecía un espacio no solo por su lenguaje antisolemne, sino por recordarnos que Nicanor Parra cantó a Manuel Rodríguez y José Miguel Carrera mucho antes que Pablo Neruda, y en la misma métrica tradicional de este romance. Además, creo que esta Aventura ya cultiva gérmenes antipoéticos que siguen madurando desde la primera parte de Poemas y antipoemas.

\section{BACHILLERATO Y CUECAS}

Parra había llegado a Valdivia en diciembre a supervisar el Bachillerato de 1961, por lo que yo solía dar ese como el año de nuestro encuentro, pero este 2014, en su casa de Las Cruces, Nicanor me corrigió ante algunos amigos: "río Valdivia 1962, Floridor", y a dos meses de cumplir sus cien años debí rendirme a la vitalidad de su memoria.

No encuentro rastros de esta permanencia entre sus biógrafos, lo que me impulsa a recordarla para evitar que se borre definitivamente la huella de este paso por la ciudad de mi adolescencia. Incluso personas muy cercanas a él me han preguntado, o más modestamente debo decir que se han preguntado a sí mismas delante de mí: “¿y qué diablos pudo haberse quedado haciendo Nicanor en Valdivia"?

Lo diré: ¡se quedó dando un curso de cueca!

Y como no me propongo desclasificar otras circunstancias personalísimas que pudieran haberlo motivado, solo recordaré hechos que, siendo anecdóticos, impliquen aprendizajes significativos que siempre aporta un encuentro con maestros verdaderos. En mi caso no fue un encuentro buscado: lo conocí invitado a una recepción que le ofrecía don Carlos Ibacache, gran animador cultural que fuera un tiempo profesor mío en la escuela primaria. 
Copa en mano, invitando a pasar a la mesa, el dueño de casa propuso, a modo de brindis:

"-iEmpecemos tomándonos un trago". Nicanor, que hasta entonces permanecía muy compuesto, celebró la frase, que repetía saboreando cada sílaba como el mejor aperitivo: "-empecé - mos - tomán- donos - un - trá - go...", y comentaba "las enormes posibilidades rítmicas de esa frase de palabras graves y esdrújulas, sin el martillazo impertinente de las agudas". Celebraba ese endecasílabo porque todavía no sentenciaba que: la poesía chilena se endecasilabó, ni mostraba intención alguna de ser aquel que la desendecasilabice...

Como suele suceder en las tertulias, hablando de todo en general y de nada en particular, entre lectores no fue raro llegar a los problemas de la vista y don Carlos, que me conoció con anteojos, intentó hacerme entrar en confianza preguntándome por mi condición actual. Respondí: -En materia de ojos, a tres metros / No reconozco ni a mi propia madre...!

Esto me hizo inmediatamente visible al poeta, que trató de entablar un diálogo a todas luces imposible en aquella larguísima mesa, pero que retomamos al concluir la recepción, cuando en la puerta me propuso acompañarlo hasta su residencial, en la Costanera.

Así me contó que un grupo le estaba pidiendo clases de cueca, idea que le gustaba pero le faltaba un músico, y le recomendé a un ex compañero de curso. Que fuera profesor normalista le pareció mérito más que suficiente, la empatía fue inmediata y al día siguiente Camilo Henríquez, seleccionado de fútbol de Valdivia y violinista de la orquesta de la Escuela Normal, llegó con su guitarra al hombro. En no más de 24 horas se habría reunido una veintena de alumnos y "el hermano de la Violeta" me asignó de inmediato una beca. Pero la cueca me ha parecido siempre una chilena graciosa y respetable, por lo que nunca ha sido mi intención maltratarla, y no iba a ser esta la ocasión de hacerlo. Sin embargo -aunque ni siquiera "de oyente", sino como un simple mirón- no me perdí ninguna clase.

Ya en el primer regreso a su residencial, apoyado en la baranda de un minúsculo embarcadero, Nicanor observaba el acompasado deslizarse de los botes de los famosos remeros valdivianos que terminaban su entrenamiento diario. A un comentario sobre la visión del paisaje que se tendría desde el río, respondí: "si quiere pasear en bote, solo dígame a qué hora y lo vengo a buscar aquí mismo...". 


\section{UN TALLER FLOTANTE}

A partir de entonces, el peripatético taller de poesía en que se había convertido la salida del curso vespertino de cueca se amplió a horario diurno y categoría navegable. De preferencia después de dormir su siesta, se instalaba en la popa del bote, animoso y despreocupado, esto último porque ignoraba mi absoluta impericia con los remos. Tras comentarios generales sacaba su inseparable cuaderno de croquis y nos aplicábamos a la lectura de algún poema en pleno proceso de elaboración. Durante este ejercicio, valiosísimo en la formación de todo poeta, me leyó varios poemas de un libro que aparecería ese año.

_"Pienso llamarlo Versos de ciego... ¿Qué te parece el título...?”

Yo rehuía preguntas así, que exigieran respuestas menos vagas que un: “-la verdad... parece que... tal vez...”. Pero ahora me sentí acorralado y no tuve más salida que jugármela:

-Mire... en realidad... creo que... no me convence... mucho...

-A ver, a ver... cómo es eso... ¿por qué?

-Es que varios poemas que me ha leído dan la impresión de ser eso... o que está imitando justamente eso: versos de ciego... entonces...

Ahora fue su respuesta la que incluyó varios: "hmm... ¿sí, ah...? Ya..."

Tal como me lo anunció, pronto reconocí los poemas de aquella tarde en su nuevo libro, que al fin llamó Versos de salón. De ese modo sumaba uno a los muchos títulos de libros desechados después de anunciarlos, y considero un privilegio haberlo visto tan de cerca aplicar el mismo mecanismo mental con que elimina poemas en un libro, versos en un poema, palabras en un verso, sílabas en una palabra, demostrándose tan maestro en el difícil arte de borrar como lo es en el arte de escribir.

\section{GRACIAS A LA POESÍA, QUE ME HA DADO TANTO}

Y en el plano afectivo de la creación, me ha dado ocasiones como esta de convertirme en el único auditor de un gran poema, pues sin comentario previo alguno, Nicanor se acomodó una tarde en la popa, abrió su cuaderno y leyó, leyó como si nadie lo oyera, o tal vez como si solo escuchara esa Viola piadosa, Viola doliente, Viola volcánica invocada: 


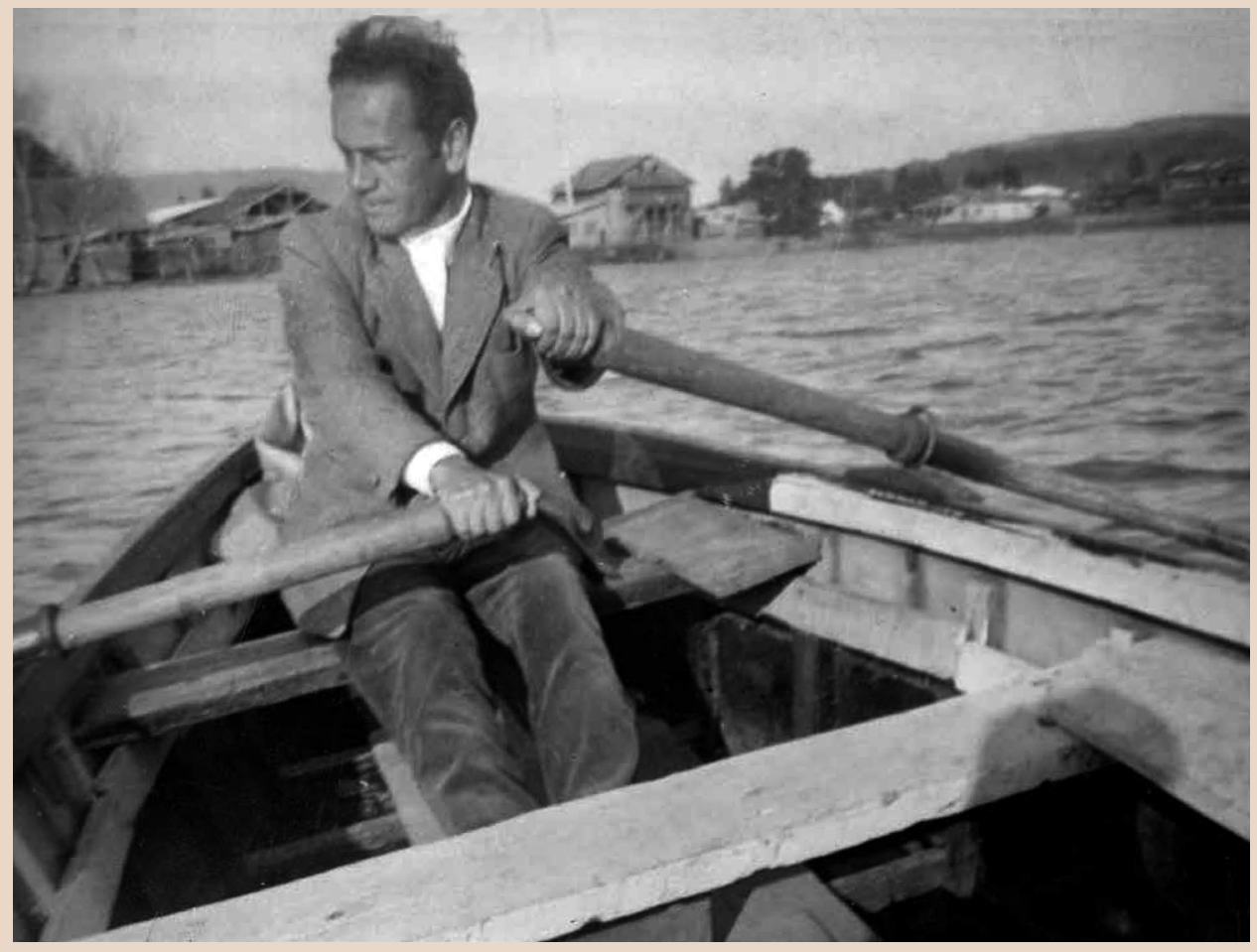

N. Parra en el río Valdivia, verano de 1962. Me admira que el poeta haya conservado por medio siglo esta imperfecta fotografía en su archivo personal, desde el cual la reprodujo el importante libro Parra a la vista ${ }^{1}$ (p. 71), publicado como parte de la celebración de su centenario.

\section{Defensa de Violeta Parra}

Dulce vecina de la verde selva, Huésped eterno del abril florido, Grande enemiga de la zarzamora: Violeta Parra....

Habitualmente, a cada lectura seguía un iluminador comentario suyo, una pregunta o hasta alguna impertinencia mía, pero esta vez guardamos

${ }^{1}$ Santiago, AIFOS Ediciones, 2014, patrocinado por la Corporación del Patrimonio Cultural de Chile, con aportes de la Minera Collahuasi y la Ley de Donaciones Culturales. 
"un profundo silencio religioso". Y la emotiva lectura de Nicanor causó tan profunda impresión en mi espíritu, que al despedirnos tuve una osadía que hasta hoy me desconozco: le dije si me prestaría su famoso cuaderno. Y para mi mayor sorpresa, me lo tendió sin pregunta ni recomendación alguna.

Trasnoché haciendo la primera copia mecanografiada del gran poema. Imitando la imprenta, ilustré su portada de cartulina de color con el típico velero de líneas rectas que los malos para el dibujo hacíamos en la escuela, cuya única gracia consistió en haberlo dibujado a máquina. Y si no gracia, al menos harta paciencia requería, pues costaba mucho trazarlo poniendo la cartulina "pallá y pacá" en el angosto carro de la máquina portátil de mi padre.

¿Y qué fue del famoso cuaderno croquis de 40 hojas? La última vez que lo vi cruzábamos los tres -Nicanor, el cuaderno y yo- sobre el Puente Calle Calle. Las estrellas simulaban una ciudad hundida en la profundidad del río, y observando ese panorama, Nicanor Parra dijo, con aires de juez que emite un fallo inapelable: "el río Valdivia es el lago más largo de Chile". Bajo el último farol del puente sacó el cuaderno, escribió algo, lo guardó y seguimos.

¿Qué escribió cruzando el puente en que crucé de mi infancia a mi adolescencia? Lo supe en 1969, en página 244 de su Obra gruesa: "El río Valdivia es el lago más largo de Chile". 